\title{
Perilaku Memilih Tenaga Penolong Persalinan pada Ibu Melahirkan di Desa Blambangan, Kecamatan Penengahan, Kabupaten Lampung Selatan, Indonesia
}

\section{THE CHOOSING BEHAVIOR OF BIRTH ATTENDANT FOR MATERNAL AT BLAMBANGAN VILLAGE, PENENGAHAN SUBDISTRICT, SOUTH LAMPUNG DISTRICT, INDONESIA}

\author{
Nurhayati $^{2}$, dan Mugeni Sugiharto ${ }^{1}$ \\ ${ }^{2}$ Pusat Penelitian dan Pengembangan Sumber Daya dan Pelayanan Kesehatan \\ Jl. Percetakan Negara No.29 Jakarta Pusat 10560 \\ ${ }^{1}$ Pusat Penelitian dan Pengembangan Humaniora dan Manajemen Kesehatan, \\ Badan Litbang Kesehatan, \\ *Email: nurhayati.litbangkes@gmail.com
}

Submitted: 27-05-2019, Revised:19-06-2019, Revised :09-07-2019, Accepted : 30-08-2019

\begin{abstract}
Maternal deaths is still high in Indonesia. Nowadays, there are still many Indonesian women helped by non-health workers in labor and delivery. To get insight about mothers' decision making in choosing the helper in labor and delivery and the factors that hamper and support it. Methods: This is a qualitative study using in-depth interview to mothers who ever had delivered a baby, the husbands, the health workers (midwifes), and shamans who help in labor and delivery. This study was done in Blambangan Village, South Lampung in the year 2008. The data was processed by grouping, making categories and chronologies, and conducting content analysis. Most of the mothers chose the shaman as the helper in labor and delivery. The factors that influence the decision were the education level; the type of job; the impact of the midwifes, shamans, transportation, mother's health status, the complication level of the labor and delivery, and the impact of the husbands. There were three factors that influence the mothers'decision making in choosing the helper in labor and delivery: 1) the predisposing factors, such as education level and type of job; 2) the reinforcing factors, such as the availability of the helper in labor and delivery and transportation; 3) the enabling factors such as the previous helper in labor and delivery, the role of the husbands, midwifes, and the shamans who help in labor and delivery. Suggestions: Labor and delivery counseling through midwifes, and constructing partnership between midwifes and shamans who help in labor and delivery are very important.
\end{abstract}

Keywords: labor and delivery, mother, shamans who help labor and delivery, midwifes

\begin{abstract}
Abstrak
Angka Kematian Ibu (AKI) karena kehamilan dan persalinan masih cukup tinggi di Indonesia. Saat ini masih banyak persalinan wanita Indonesia ditolong oleh tenaga non kesehatan. Tujuan penelitian ini untuk memperoleh informasi yang mendalam tentang keputusan ibu yang pernah melahirkan dalam memilih tenaga penolong persalinan dan faktor yang menghambat dan menunjang dengan pengambilan keputusan tersebut. Metode yang digunakan merupakan penelitian kualitatif melalui wawancara mendalam kepada ibu yang pernah melahirkan, suami ibu yang pernah melahirkan, petugas kesehatan (bidan), dan dukun bayi. Penelitian ini dilakukan di desa Blambangan, Lampung Selatan pada tahun 2008. Pengolahan data dilakukan dengan cara mengelompokkan, membuat kategori dan kronologisnya, serta melakukan analisis isi. Hasilnya diketahui sebagian besar ibu memilih dukun bayi sebagai tenaga penolong persalinannya. Faktor yang mempengaruhi ibu memilih tenaga penolong persalinan adalah tingkat pendidikan, jenis pekerjaan, pengaruh bidan, dukun, transportasi, masalah kesehatan ibu, faktor kesulitan persalinan, dan pengaruh suami. Kesimpulan yang diperoleh dari peneliti ini terdapat 3 faktor yang mempengaruhi ibu
\end{abstract}


memilih penolong persalinan yaitu 1) faktor pemicu seperti tingkat pendidikan dan jenis pekerjaan; 2) faktor pemungkin seperti ketersediaan penolong persalinan, dan transportasi;3) faktor penguat seperti penolong persalinan sebelumnya, peran suami, bidan dan dukun bayi. Saran: Pentingnya penyuluhan persalinan melalui bidan dan membangun kemitraan antara bidan dan dukun yang saling menguntungkan.

Kata kunci: Persalinan, Ibu, Dukun bayi, Bidan

\section{PENDAHULUAN}

Keberhasilan program kesehatan ibu di suatu daerah, dapat dilihat dari indikator Angka Kematian Ibu (AKI). Penurunan AKI menjadi penting bagi suatu negara, karena nilai AKI merupakan indikator kesehatan masyarakat dan selalu menjadi indikator pembangunan kesehatan dalam setiap RPJMN termasuk RPJMN 20152019 dan SDGs. ${ }^{1}$ Upaya pemerintah melalui Kementerian Kesehatan RI, terhadap kesehatan ibu sejak tahun 2007 adalah melakukan percepatan penurunan AKI. Kebijakan penurunan AKI di antaranya adalah pencanangan program peningkatan pelayanan kesehatan reproduksi, peningkatan pemberantasan penyakit menular dan imunisasi, peningkatan pelayanan kesehatan dasar dan rujukan, penanggulangan Kekurangan Energi dan Kalori (KEK), serta penanggulangan anemia zat gizi besi pada wanita usia subur, masa kehamilan, melahirkan dan nifas.

Menurut WHO, permasalahan kesehatan reproduksi ibu pada fase kehamilan dan nifas di negara berkembang adalah masih banyak ibu yang melahirkan di rumah dan ditolong oleh dukun bayi (tenaga non kesehatan). Salah satu penyebabnya adalah keterbatasan ekonomi. Berdasarkan hasil Riskesdas 2010, ibu yang melahirkan di rumah, sebesar $40,2 \%$ proses persalinan ditolong dukun bayi. ${ }^{2}$ Oleh karena itu, sampai saat ini Indonesia masih mengalami permasalahan AKI. Sebelum tahun 2007 terdapat penurunan AKI, tetapi sejak tahun 2007 terjadi peningkatan AKI dari 228 per 100.000 menjadi 359 per 100.000 kelahiran hidup (SDKI 2012), dan 305 per 100.000 kelahiran hidup tahun 2015 (SUPAS 2015). ${ }^{3}$

Salah satu faktor yang dapat mempengaruhi ibu untuk memilih tempat bersalin dan tenaga yang menolong persalinan adalah kondisi geografis dan transportasi yang sulit, budaya dan tradisi etnis $^{4}$, seperti masih ada budaya masyarakat menggunakan dukun laki-laki khusus untuk menolong persalinan yang sulit. ${ }^{5}$ Kasus persalinan di rumah dengan dukun bayi sebagai penolong persalinan juga terjadi di Kabupaten Lampung Selatan, khususnya di Kecamatan Penengahan. Desa Blambangan mempunyai angka cakupan ibu bersalin ditolong tenaga kesehatan yang paling rendah. Dampak dari masih banyaknya persalinan menggunakan dukun di Kabupaten Lampung Selatan mengakibatkan AKI masih tinggi 74 per 100.000 kelahiran hidup pada tahun 2008 yang disertai kematian bayi (AKB) mencapai 5,67 per 1.000 kelahiran hidup. ${ }^{6}$

Untuk mengetahui secara mendalam penyebab kasus persalinan ibu melalui dukun tersebut, telah dilakukan penelitian di Desa Blambangan, Kecamatan Penengahan, Kabupaten Lampung Selatan tahun 2008 melalui studi kualitatif. Penelitian ini bertujuan untuk memperoleh informasi yang mendalam tentang faktor yang berhubungan dengan perilaku memilih tenaga penolong persalinan pada ibu yang pernah melahirkan di Desa Blambangan, Kecamatan Penengahan, Kabupaten Lampung Selatan. Hasil penelitian ini dapat memberikan kontribusi informasi secara kualitatif untuk mendukung prioritas Program Kesehatan Ibu dan Anak (KIA) untuk menurunkan AKI dan AKB, melalui pengurangan fungsi dukun dalam memberikan pertolongan persalinan.

\section{BAHAN DAN METODE}

Penelitian ini merupakan studi kasus jenis penelitian kualitatif, dengan melakukan wawancara mendalam kepada informan (sumber informasi). Lokasi penelitian di Desa Blambangan, Kecamatan Penengahan, Kabupaten Lampung Selatan. Sumber informasi atau informan pada penelitian ini adalah ibu yang pernah melahirkan, suami ibu yang pernah melahirkan, petugas kesehatan (bidan) dan dukun bayi. Jumlah informan 18 orang terdiri dari ibu yang pernah melahirkan sebanyak 8 orang, suami dari ibu yang pernah melahirkan sebanyak 4 orang, bidan 
berjumlah 2 orang, dan dukun bayi berjumlah 4 orang. Pengumpul data dilakukan oleh peneliti yang berlatar belakang kesehatan masyarakat.

Pengolahan dan analisis data menggunakan EZ-text. Proses pengolahan dan analisis data diawali dengan membuat catatan yang lengkap tentang proses dan hasil wawancara mendalam, kemudian dientri dan dikelompokkan berdasarkan kategori dan kronologis. Uji keabsahan data dilakukan dengan teknik triangulasi, dengan menggunakan informan yang berbeda, yaitu ibu, suami ibu, dan tenaga penolong persalinan (bidan dan dukun bayi). Hasil jawaban seorang informan dibandingkan dengan informan lainnya. Etik penelitian diajukan kepada komite etik Fakultas Kesehatan Masyarakat Universitas Indonesia.

\section{HASIL}

\section{Karakteristik Informan}

Karakteristik informan dalam penelitian ini, disajikan pada Tabel 1.

\section{Pengetahuan tentang Tenaga Penolong Persalinan.}

Hasil penelitian terkait pengetahuan tentang siapa tenaga penolong persalinan dan pendapat tentang pelayanan tenaga penolong persalinan, disajikan pada Tabel 2 .

Tabel 2. Pengetahuan Ibu tentang Tenaga Penolong Persalinan di Desa Blambangan Kecamatan.

\section{Penengahan, Kabupaten Lampung Selatan Tahun 2008.}

Semua ibu mengatakan selain bidan juga ada dukun bayi di desa mereka. Pendapat tentang pelayanan persalinan oleh dukun bayi, secara umum informan mengatakan baik, hanya ada satu orang yang mengatakan bidan dan dukun kadang ada dan tidak ada di tempat, sehingga menyulitkan ibu yang minta tolong untuk proses persalinan.

\section{Motivasi memilih tenaga penolong persalinan}

Informasi motivasi, terkait pertanyaan pilihan tenaga penolong persalinan dan alasan memilih tenaga persalinan, disajikan pada Tabel 3.

Tabel 1. Gambaran Karakteristik Informan di Desa Blambangan Kecamatan Penengahan Kabupaten Lampung Selatan Tahun 2008

\begin{tabular}{|c|c|c|c|}
\hline Informan & Umur (Tahun) & Pendidikan & Pekerjaan \\
\hline Ibu 1 & 38 & SMP & Ibu rumah tangga \\
\hline Ibu 2 & 28 & SMP & Ibu rumah tangga \\
\hline Ibu 3 & 38 & SD & Ibu rumah tangga \\
\hline Ibu 4 & 31 & $\mathrm{SD}$ & Ibu rumah tangga/kader \\
\hline Ibu 5 & 35 & SMP & Ibu rumah tangga/kader \\
\hline Ibu 6 & 30 & SD & Ibu rumah tangga \\
\hline Ibu 7 & 26 & SD & Ibu rumah tangga \\
\hline Ibu 8 & 22 & SMA & Ibu rumah tangga \\
\hline Bapak 1 & 32 & SD & Buruh \\
\hline Bapak 2 & 35 & SMA & Pengurus truk \\
\hline Bapak 3 & 34 & SD & Pedagang \\
\hline Bapak 4 & 30 & SMP & Buruh bangunan \\
\hline Bidan 1 & 22 & D3 kebidanan & Bidan desa \\
\hline Bidan 2 & 39 & D1 kebidanan & Bidan desa \\
\hline Dukun bayi 1 & 70 & Tidak sekolah & Dukun bayi \\
\hline Dukun bayi 2 & 48 & SD & Dukun bayi \\
\hline Dukun bayi 3 & 53 & SD & Dukun bayi \\
\hline Dukun bayi 4 & 70 & SD & Dukun bayi \\
\hline
\end{tabular}


Tabel 2. Pengetahuan Ibu tentang Tenaga Penolong Persalinan di Desa Blambangan Kecamatan Penengahan, Kabupaten Lampung Selatan Tahun 2008

\begin{tabular}{cll}
\hline Informan & \multicolumn{1}{c}{ Siapa saja tenaga penolong persalinan } & \multicolumn{1}{c}{ Pendapat tentang pelayanan tenaga penolong persalinan } \\
\hline Ibu 1 & Dukun bayi, bidan & Keduanya baik \\
Ibu 2 & Dukun bayi, bidan & Keduanya baik \\
Ibu 3 & Dukun bayi, Bidan & Baik, bidan teliti dan sabar \\
Ibu 4 & Dukun bayi, bidan & Keduanya lumayan, enak, cepat,tanggap \\
Ibu 5 & Bidan desa, dukun & Dua-duanya baik. \\
Ibu 6 & Dukun bayi, bidan & Keduanya lumayan nyaman, perawatannya enak \\
Ibu 7 & Dukun bayi, Bidan & Dua-duanya baik \\
Ibu 8 & Dukun bayi, bidan & Keduanya terkadang ada, bidan pelayanannya cepat \\
\hline
\end{tabular}

Tabel 3. Motivasi Ibu Memilih Tenaga Penolong Persalinan di Desa Blambangan Kecamatan Penengahan, Kabupaten Lampung Selatan Tahun 2008

\begin{tabular}{|c|c|c|}
\hline Informan & Tenaga penolong persalinan yang dipilih & Alasan memilih tenaga penolong persalinan tersebut \\
\hline Ibu 1 & Dukun bayi & $\begin{array}{l}\text { Sejak anak pertama,makai dukun. Ke bidan bila ada } \\
\text { masalah }\end{array}$ \\
\hline Ibu 2 & Dukun bayi & Sudah percaya dukun bayi \\
\hline Ibu 3 & Bidan & Karena ada riwayat darah tinggi \\
\hline Ibu 4 & Bidan & Kalau ada apa-apa cepat \\
\hline Ibu 5 & Dukun bayi & \\
\hline Bidan & $\begin{array}{l}\text { Kondisi ekonomi, kalau dukun bayi biayanya dapat } \\
\text { terserah }\end{array}$ & \\
\hline \multicolumn{3}{|l|}{ Bila ada kesulitan } \\
\hline Ibu 6 & Dukun bayi & Nenek sendiri dan kalau ke bidan biayanya berat \\
\hline Ibu 7 & Pertama ke dukun bayi & Karena keluarga biasa ke dukun bayi, biaya sekedarnya \\
\hline Ibu 8 & Bidan & Pelayanannya cepat dan mudah \\
\hline
\end{tabular}

Tabel 4. Ketersediaan Tenaga Penolong Persalinan Menurut Informan Suami Ibu di Desa Blambangan Kecamatan Penengahan, Kabupaten Lampung Selatan Tahun 2008

\begin{tabular}{lll}
\hline Informan & Jumlah tenaga penolong persalinan & Kemudahan menghubungi/ menggunakan tenaga penolong persalinan \\
\hline Bapak 1 & 3 dukun bayi, 1 bidan & Dukun bayi dekat jaraknya, dahulu bidan jauh \\
Bapak 2 & 2 dukun bayi, 1 bidan & Lumayan, cepat, dan tanggung jawab \\
Bapak 3 & Bidan, dukun bayi & Bidan hanya 1 orang, sering tidak ada di tempat, \\
Bapak 4 & Bidan, dukun bayi & Keduanya mudah \\
\hline
\end{tabular}

Tabel 5. Kemudahan Mencapai Tenaga Penolong Persalinan menurut Informan Ibu dan Suami di Desa Blambangan Kecamatan Penengahan, Kabupaten Lampung Selatan Tahun 2008

\begin{tabular}{lll}
\hline Informan & Jarak ke tenaga penolong persalinan & $\begin{array}{l}\text { Jenis alat transportasi yang digunakan ke tempat tenaga penolong } \\
\text { persalinan }\end{array}$ \\
\hline Ibu 1 & Ke dukun bayi dekat, dan ke bidan jauh & Ke dukun Jalan kaki, tapi naik ojek ke bidan \\
Ibu 2 & Ke dukun bayi dekat, dan ke bidan jauh & Ke bidan naik ojek, ke dukun cukup jalan kaki \\
Ibu 3 & Dekat & Jalan kaki ke dukun bayi, naik ojek ke bidan \\
Ibu 4 & Dekat & Jalan kaki/naik ojek. karena Polindes dekat \\
Ibu 5 & Dekat & Jalan kaki ke dukun bayi, naik ojek ke bidan pulangnya diantar mobil dari bidan \\
Ibu 6 & Dekat & Ke bidan naik ojek \\
Ibu 7 & Dekat & Jalan kaki, naik ojek \\
Ibu 8 & Dekat & Jalan kaki \\
Bapak 1 & Dekat & Jalan kaki \\
Bapak 2 & Dekat & Jalan kaki \\
Bapak 3 & Dekat & Jalan kaki \\
Bapak 4 & Dekat & Ojek ke bidan \\
\hline
\end{tabular}


Tenaga penolong persalinan yang dipilih ibu adalah dukun bayi (5 informan), dengan alasan sejak anak pertama menggunakan dukun bayi, sudah percaya dengan dukun bayi, biayanya dapat terserah ibu atau sekedarnya. Sementara yang memilih penolong persalinan bidan adalah karena ibu mempunyai riwayat darah tinggi atau sedang sakit dan pelayanannya cepat dan mudah. Ibu pergi bersalin ke bidan jika proses persalinan mengalami kesulitan.

\section{Ketersediaan Tenaga Penolong Persalinan di Desa Blambangan Kabupaten. Lampung Selatan}

Informasi ketersediaan tenaga penolong persalinan terkait pertanyaan jumlah tenaga penolong persalinan dan kemudahan menggunakan tenaga penolong persalinan, disajikan pada Tabel 4.

Terdapat 5 orang dukun bayi dan 2 orang bidan sebagai tenaga penolong persalinan ibu di Desa Blambangan dan setiap dusun terdapat 1 orang bidan. Menurut informan, untuk kemudahan menghubungi, dukun bayi mudah dihubungi karena jaraknya dekat, sementara bidan sulit dihubungi karena jaraknya jauh, selain itu seorang informan mengatakan sulit menghubungi bidan karena sering tidak ada di tempat.

\section{Kemudahan Mencapai Tenaga Penolong Persalinan}

Terkait jarak dan jenis transportasi yang digunakan, disajikan pada Tabel 5.

\section{Pengalaman Ibu Ditolong oleh Tenaga Penolong Persalinan}

Pengalaman ibu ditolong oleh tenaga penolong persalinan, disajikan pada Tabel 6 .

Umumnya persalinan ibu ditolong oleh dukun bayi dengan alasan, ibu sejak anak pertama sudah ditolong oleh dukun bayi dan proses kelahiran lancar, ada juga yang menjawab bersalin melalui dukun biayanya terjangkau, ada juga yang beranggapan selalu lancar bersalin jika ditolong dukun. Informan yang ditolong bidan saat bersalin, mengatakan ke bidan karena kondisi ibu sedang sakit tekanan darah tinggi dan jika ada kesulitan saat melahirkan, seperti pecah ketuban, ada juga yang menjawab jika ditolong bidan maka proses bersalin lancar. Ada juga yang bersalin di rumah sakit, karena mengalami masalah kehamilan seperti jalan lahir tertutup dan tidak bisa lahir-lahir dan karena operasi cesar.

\section{Peran Suami Terhadap Keputusan Memilih Tenaga Penolong Persalinan}

Peran suami dalam proses persalinan, terkait saran yang diberikan kepada istri dalam memilih penolong persalinan dan alasan memberikan saran tersebut, disajikan pada Tabel 7 .

Semua suami menyarankan istrinya bersalin pada bidan, bukan pada dukun bayi, kecuali 2 informan suami yang menyarankan istrinya ke dukun bayi, tetapi hanya sebatas mengurut ibu dan bayinya setelah melahirkan. Adapun alasan informan suami menyarankan istrinya bersalin ke bidan, karena sudah ada bidan dan zaman sudah maju, bidan lebih tahu kondisi kesehatan kehamilan, supaya enak dan biayanyapun terjangkau, supaya istri dan anaknya selamat.

\section{Peran Petugas Kesehatan (Bidan) terhadap Keputusan Ibu dalam Memilih Tenaga Persalinan}

Peran bidan terkait pertanyaan pelayanan yang diberikan dan biaya pelayanan, sehingga memotivasi keputusan ibu memilih bidan sebagai penolong persalinan, jawaban disajikan pada Tabel 8.

Jenis pelayanan bidan kepada ibu, di antaranya memberikan penyuluhan kepada ibu hamil yang datang ke Posyandu dan kelas ibu. Kegiatan kelas ibu, materi penyuluhan berdasarkan masalah yang sedang dihadapi dan memotivasi ibu untuk melahirkan melalui bidan. Pada saat kunjungan ibu memeriksakan kehamilan, bidan memberikan motivasi kepada ibu hamil, agar melahirkan dengan tenaga kesehatan (bidan). Jenis pelayanan lainnya yaitu menangani persalinan, memantau ibu bersalin dari hari pertama (6 jam setelah persalinan) sampai 7 hari persalinan. Disisi lain, bidan juga bermitra dengan dukun bayi. Sementara biaya persalinan melalui bidan sudah ada patokannya dan bisa dibayar dicicil atau menggunakan kartu Askeskin bila mempunyai kartu tersebut.

Pendapat bidan terkait pemanfaatan penolong persalinan oleh ibu, disajikan pada Tabel 10. 
Tabel 6. Pengalaman Ibu Ditolong Tenaga Penolong Persalinan di Desa Blambangan Kecamatan Penengahan, Kabupaten Lampung Selatan Tahun 2008

\begin{tabular}{|c|c|}
\hline Informan & Pengalaman melahirkan dengan bantuan tenaga penolong persalinan \\
\hline Ibu 1 & Sejak anak pertama sampai anak ke empat ditolong dukun bayi dan lancar \\
\hline Ibu 2 & Dengan dukun bayi dan lancar \\
\hline Ibu 3 & $\begin{array}{l}\text { Memanggil bidan ke rumah, karena pecah ketuban, tensi ibu tinggi, sehingga dirujuk ke rumah sakit. Melahirkan } \\
\text { anak 1-3 dengan dukun bayi dan anak ke empat dengan bidan. Ibu punya darah tinggi sehingga disarankan bidan } \\
\text { melahirkan di rumah sakit. Sehabis melahirkan diurut oleh dukun bayi }\end{array}$ \\
\hline Ibu 4 & Dengan bidan dan lancar \\
\hline Ibu 5 & Dengan bidan karena kondisi ibu sedang sakit \\
\hline Ibu 6 & Dengan dukun bayi karena biaya terjangkau \\
\hline Ibu 7 & $\begin{array}{l}\text { Pertama dukun karena tidak lahir, memanggil bidan, juga tidak lahir lalu dibawa ke dokter, dicoba dengan vacuum } \\
\text { tapi gagal, akhirnya dioperasi cesar }\end{array}$ \\
\hline Ibu 8 & $\begin{array}{l}\text { Pertama ke dokter untuk periksa USG. Hasilnya jalan lahirnya tertutup. Lalu ke bidan, periksa USG lagi hasilnya } \\
\text { masih tertutup maka dibawa ke rumah sakit }\end{array}$ \\
\hline
\end{tabular}

Tabel 7. Saran Suami dalam Memilih Tenaga Penolong Persalinan di Desa Blambangan Kecamatan Penengahan, Kabupaten Lampung Selatan Tahun 2008

\begin{tabular}{lll}
\hline \multicolumn{1}{c|}{ Informan } & \multicolumn{1}{c}{$\begin{array}{c}\text { Saran yang diberikan kepada istri dalam memilih tenaga } \\
\text { penolong persalinan }\end{array}$} & Alasan memberikan saran \\
\hline Bapak 1 & $\begin{array}{l}\text { Lahir anak pertama tidak di rumah jadi tidak tahu. Kelahiran } \\
\text { berikutnya sarankan ke bidan Dukun bayi diperlukan mengurut } \\
\text { ibu-bayinya }\end{array}$ & Sudah ada bidan dan zaman sudah maju \\
Bapak 2 & Ke bidan & Lebih tahu kondisinya \\
Bapak 3 & Pertama ke dukun dahulu baru ke bidan & $\begin{array}{l}\text { Lebih tahu kondisinya Karena saran orang tua } \\
\text { dan ke bidan Supaya enak dan biayanya tidak } \\
\text { besar Khawatir atas kondisi istri agar istri dan } \\
\text { anak selamat }\end{array}$ \\
Bapak 3 & Pertama ke dukun dahulu baru ke bidan & Karena saran orang tua dan ke bidan \\
Bapak 4 & Ke bidan & \\
\hline
\end{tabular}

Tabel 8. Peran Bidan terhadap Ibu dalam Memilih Tenaga Penolong Persalinan di Desa Blambangan Kecamatan Penengahan, Kabupaten Lampung Selatan Tahun 2008

\begin{tabular}{|c|c|c|}
\hline Informan & Pelayanan dari petugas kesehatan & Biaya pelayanan \\
\hline Bidan 1 & $\begin{array}{l}\text { Penyuluhan kepada ibu melalui Posyandu, } \\
\text { menangani persalinan, memantau ibu } \\
\text { bersalin } 6 \text { jam sampai } 7 \text { hari setelah } \\
\text { persalinan, } \\
\text { 1. Hari pertama memantau apakah bayi } \\
\quad \text { mau menetek atau tidak dan menensi } \\
\text { ibunya } \\
\text { 2. } 3 \text { hari kemudian datang memantau } \\
\text { ibu-bayi } \\
\text { 3. } 7 \text { hari datang kembali }\end{array}$ & $\begin{array}{l}\text { Ada patokannya, karena ada pemberian obat, } \\
\text { tenaga/jasanya yang sudah ada standarnya. }\end{array}$ \\
\hline
\end{tabular}




\begin{tabular}{|c|c|}
\hline Informan & Pemanfaatan tenaga penolong persalinan oleh ibu bersalin \\
\hline Bidan 1 & $\begin{array}{l}60 \% \text { ke dukun, mungkin faktor biaya ke dukun seikhlasnya, biaya di bidan ada patokannya. Faktor sosial budaya, } \\
\text { dukun lebih berpengalaman karena sudah tua. }\end{array}$ \\
\hline Bidan 2 & $\begin{array}{l}\text { Rasa takut pada bila tidak memanfaatkan dukun. Takut dimarahi orang tuanya. Ada kesan dukun menyalahkan keluarga } \\
\text { bila bermasalah pada waktu melahirkan, jika tidak manggil bidan. Sama jumlah ibu ke dukun dan ke bidan. Ada kesan } \\
\text { dukun kurang bekerjasama dengan bidan. Bila pendarahan baru memanggil bidan }\end{array}$ \\
\hline
\end{tabular}

Tabel 11. Peran Dukun Bayi terhadap Ibu dalam Memilih Tenaga Penolong Persalinan di Desa Blambangan Kecamatan Penengahan, Kabupaten Lampung Selatan Tahun 2008

\begin{tabular}{|c|c|c|}
\hline Informan & Jenis pelayanan yang diberikan & Biaya pelayanan \\
\hline Paraji 1 & $\begin{array}{l}\text { Memeriksa ibu di usia kehamilan } 1-2 \text { bulan, melayani urut ibu hamil, } \\
\text { motong ari-ari dengan bambu, bersihkan badan bayi dan ibunya, rawat } \\
\text { ibu bersalin sampai } 40 \text { hari, } 3 \text { hari diurut } 7 \text { hari diurut, } 40 \text { hari diurut, } \\
\text { sampai selesai masa nifas, bisa dipanggil ke rumah }\end{array}$ & $\begin{array}{l}\text { Terserah ibu bersalin, tidak dipatok, } \\
\text { seikhlasnya }\end{array}$ \\
\hline Paraji 2 & $\begin{array}{l}\text { Bantu paraji } 1 \text { nangani ibu bersalin, urus bayi ibu bersalin, urut bayi } \\
\text { sampai } 7 \text { hari }\end{array}$ & Seikhlasnya \\
\hline Paraji 3 & $\begin{array}{l}\text { Bantu persalinan ibu yang bermasalah, seperti lahir miring atau pantat } \\
\text { lebih dulu, mengurut ibu dan bayinya }\end{array}$ & Terserah ibu bersalin \\
\hline Paraji 4 & $\begin{array}{l}\text { Bila bumil sering sakit tiap menit, maka akan menunggui dan mengelus } \\
\text { ibu yang akan bersalin tersebut, memotong ari-ari dengan gunting yang } \\
\text { sudah disiram air panas, mengurus ibu dan bayinya, hari ke tiga dan ke } 7 \\
\text { mengontrol dan mengurut ibunya }\end{array}$ & Terserah ibu bersalin \\
\hline
\end{tabular}

Pendapat informan bidan terkait pemanfatan tenaga penolong persalinan, bahwa perkiraan $60 \%$ ibu-ibu masih ke dukun bayi sebagai penolong persalinannya, alasannya disebabkan biaya bersalin ke dukun seikhlasnya dan dukun bayi lebih berpengalaman, karena usianya sudah tua. Pemanfaatan ibu terhadap tenaga persalinan, sama banyaknya antara ibu yang memanfaatkan dukun bayi dan bidan. Ibu masih memiliki rasa takut apabila tidak ditolong oleh dukun bayi. Informan lain menambahkan, ada kesan dukun bayi menyalahkan keluarga bila ada masalah dalam proses bersalin dan ada kesan dukun bayi kurang bekerjasama dengan bidan. Dukun bayi akan memanggil bidan, jika ibu terjadi pendarahan saat melahirkan.

\section{Peran dukun bayi terhadap keputusan ibu memilih tenaga persalinan}

Selain peran bidan, juga ditanyakan peran dukun bayi dalam mempengaruhi keputusan ibu memilih tenaga persalinan, disajikan pada Tabel11.

Menurut informan dukun bayi, bahwa mereka memberikan semua pelayanan persalinan, tetapiada 1 orang dukun bayi yang hanya membantu duluan bayi yang lebih tua dalam menolong persalinan. Semua informan mengatakan bahwa mereka mengurut ibu dan bayinya, memeriksa perut ibu hamil pada usia kehamilan 1 atau 2 bulan, bila ibu hamil tidak enak badan, maka akan diurut, memotong ari-ari dengan bambu/sembilu, membersihkan badan ibu dan bayi, mengurut ibu dan bayi pada hari ketiga, ketujuh, dan hari ke empat puluh. Seorang informan mengungkapkan bahwa pernah menangani persalinan yang bermasalah seperti lahir miring atau lahir pantat lebih dulu, tapi dapat lahir dengan selamat. Seorang informan dukun bayi lainnya mengatakan ketika ibu sudah merasakan sakit pertanda mau melahirkan, maka dukun bayi mengelus-elus perut ibu dan menungguinya sampai melahirkan.

\section{PEMBAHASAN}

Permasalahan AKI di Indonesia menurut Kepmenkes No.603/2008 masih cukup tinggi, sehingga upaya penurunan AKI masih menjadi prioriotas utama dalam pembangunan kesehatan. Kebijakan penurunan AKI sesuai amanat UU NO 39/2016 merupakan kebijakan utama dalam upaya pokok kesehatan melalui program kesehatan ibu dan anak (KIA), salah satunya adalah pemenuhan akses pelayanan kesehatan ibu dan anak sebagai strategi utama pembangunan kesehatan 2015-2019 di Indonesia, sehingga pemerintah menempatkan 
bidan di setiap desa di Indonesia. Meski bidan sudah tersebar di seluruh desa di Indonesia, namun persalinan melalui dukun bayi masih ada hingga saat ini di Desa Blambangan Kecamatan Penengahan Kabupaten Lampung Selatan. ${ }^{7}$

Hasil penelitian menunjukkan sebagian besar ibu memilih dukun bayi sebagai penolong persalinan dan memilih bidan apabila ibu mengalami gangguan kesehatan dan gangguan persalinan. Hal ini menunjukkan dukun bayi di Kabupaten Lampung Selatan memiliki peran kuat mempengaruhi pilihan persalinan ibu. Kasus seperti ini juga terjadi di Kabupaten Kendari, menurut hasil penelitian Anggorodi Rina bahwa peran dukun bayi di masyarakat masih cukup signifikan dalam menentukan persalinan ibu, bahkan masyarakat lebih senang ditolong oleh dukun bayi laki-laki. ${ }^{8}$ Menurut hasil penelitian Amilda sebanyak 55,6\% ibu di desa Banjarsari Kabupaten Magelang memilih persalinan dengan dukun bayi. ${ }^{9}$

Terkait masih adanya tradisi dalam mempengaruhi keputusan keluarga memilih dukun bayi sebagai penolong persalinan. hal itu merupakan salah satu kebudayaan Indonesia yang masih ada dan diwariskan turun temurun. ${ }^{10}$ Kepercayaan pada dukun bayi, disebabkan karena dukun bayi mengetahui tradisi pantangan (larangan) bagi ibu hamil dan ibu bersalin di wilayah itu, agar ibu dan bayi selamat. Pantangan (larangan) yang disampaikan dukun bayi di antaranya adalah larangan makan durian bagi ibu hamil dan larangan ibu hamil keluar sore. ${ }^{11}$

Tradisi masyarakat lebih mempercayai dukun bayi untuk menolong persalinan, karena dukun ramah, juga terjadi di Provinsi Jawa Timur. Sesuai hasil penelitian Pramono dan Sadewo (2011) di Jawa Timur, bahwa masyarakat Jawa Timur memilih dukun bayi saat proses persalinan. karena dukun bayi ramah dan selalu melibatkan suami dan famili, untuk ikut berpartisipasi menolong proses kelahiran. ${ }^{12}$ Tradisi persalinan dengan bantuan dukun bayi tidak hanya terjadi di perdesaan, tetapi juga di perkotaan, seperti sebagian besar penolong persalian masyarakat KabupatenTangerang dilakukan oleh dukun bayi. ${ }^{8}$ Dari jawaban semua informan terhadap keputusan memilih tenaga penolong persalinan dapat dikelompokkan menjadi 3 faktor yaitu 1) faktor pemicu; 2) faktor pemungkin dan 3) faktor penguat.

\section{Faktor Pemicu Ibu Memilih Tenaga Penolong Persalinan}

Faktor pemicu merupakan faktor yang mendasari ibu termotivasi memilih tenaga penolong persalinan dapat dilihat menurut karakteristik seperti umur, pendidikan, pekerjaan, pengetahuan ibu tentang tenaga penolong persalinan, pemilihan tenaga penolong persalinan dan alasan memilih tenaga penolong. ${ }^{13,14}$

Jadi pemicu ibu memilih penolong persalinan adalah karena adanya perbedaan pengetahuan persalinan. Ibu yang berpendidikan tinggi dan ibu sebagai kader kesehatan memiliki pengetahuan persalinan yang benar akan memilih bidan desa, sebaliknya ibu yang berpendidikan rendah dan tidak mengetahui makna persalinan secara benar, memilih dukun bayi dalam proses persalinannya. Pengetahuan persalinan ibu membentuk persepsi yang berbeda antara ibu satu dengan yang lainnya terhadap siapa penolong persalinannya. Hal ini sejalan dengan hasil penelitian Een Kurnaesih, bahwa persepsi ibu tentang persalinan menjadi dasar ibu mengambil keputusan siapa penolong persalinan. ${ }^{15}$

Selain itu, motivasi ibu memilih bidan karena pengaruh suami dan adanya faktor penyulit persalinan yang tidak mampu ditangani dukun bayi. Dukun akan merujuk pasiennya ke bidan, jadi bidan di desa ini hanya sebagai orang kedua, setelah dukun bayi. Kondisi ibu yang dirujuk umumnya sudah lemah. Tidak jarang kasus seperti ini akan berakhir dengan kematian, karena keterlambatan memberikan pertolongan secara medis. Salah satu penyebab kematian ibu bersalin dan bayi di Indonesia adalah karena keluarga terlambat membuat keputusan, terlambat mengantar persalinan dan terlambat memperoleh penanganan persalinan yang tepat. ${ }^{16}$

Sementara pemicu lain keputusan ibu memilih dukun sebagai penolong persalinan adalah termotivasi pada kemampuan dukun yang menolong persalinan pertamanya selamat dan mudah, serta kesediaan dukun ikut merawat ibu bersalin dan bayi selama 40 hari sampai masa nifas selesai, serta biaya murah terjangkau yang didasarkan pada keikhlasan. Sikap empati dukun bayi seperti ini yang sering terlupakan oleh bidan. Oleh karena itu meskipun bidan sudah melaksanakan program Making Pregnancy Safer (MPS) di wilayah kerjanya, tetap saja masyarakat mengutamakan dukun bayi. Menurut 
hasil penelitian Saddiyah Rungkuti dukun bayi seharusnya sebagai pendamping bidan dalam menolong persalinan dan dukun bayi wajib memiliki pengetahuan standar penanganan kelahiran yang aman. ${ }^{16}$

Program kemitraan bidan dan dukun bayi telah dicanangkan pemerintah sejak tahun 2002 dengan tujuan untuk meningkatkan cakupan pertolongan persalinan oleh tenaga kesehatan. Dukun bayi sebagai penolong persalinan didorong supaya menjadi mitra pendamping bagi bidan yang menolong persalinan melalui mekanisme kerjasama yang saling menguntungkan. ${ }^{17}$

Peran dukun dalam kemitraaan untuk merawat ibu dan bayi pada masa nifas, sehingga masyarakat masih merasakan dekat dengan dukun dan tidak menyalahi tradisi di wilayah itu. Bentuk kemitraan bidan dengan dukun adalah dukun dan bidan bisa bekerja sama untuk persalinan aman, dukun bayi membacakan doa-doa dan mendorong bayi lahir, agar persalinan lancar dan aman. ${ }^{18}$

Masih dipercayanya dukun bayi di Indonesia pada umumnya tidak lepas dari pelaksanaan program kesehatan ibu dan anak yang belum optimal menyentuh hati kaum ibu. Program KIA terfokus pada penurunan AKI dan AKB melalui model pelayanan kedokteran modern, tetapi belum aspek sosial di masyarakat. Hasil penelitian Amalia, menunjukkan bahwa dukun bayi masih dipercaya sebagian besar masyarakat Indonesia, karena dukun bayi sebagai tokoh informal yang dituakan dan memiliki keilmuan yang diwariskan turun temurun. Dukun bayi mempunyai kharisma seperti kewibawaan, sehingga dapat membangun citra dukun di hati masyarakat. ${ }^{19}$

\section{Faktor Pemungkin Bagi Ibu dalam Memilih Tenaga Penolong Persalinan}

Faktor pemungkin adalah faktor yang memungkinkan bagi ibu memilih tenaga penolong persalinan di Kabupaten Lampung Selatan di antaranya berdasarkan ketersediaan tenaga penolong persalinan dan kemudahan mencapai tenaga penolong persalinan, baik bidan maupun dukun bayi di wilayahnya, seperti ibu bersalin lebih memilih dukun bayi dari pada bidan, karena jarak ke dukun bayi lebih dekat dan cukup berjalan kaki dari pada pergi ke bidan yang jauh dan harus naik ojek. Hasil penelitian ini sejalan dengan hasil penelitian Amilda yang menyatakan bahwa responden yang memilih pertolongan persalinan dengan dukun bayi umumnya merupakan masyarakat yang jarak rumahnya dekat menuju tempat dukun bayi. ${ }^{9}$

\section{Faktor Penguat Bagi Ibu dalam Memilih Tenaga Penolong Persalinan}

Faktor penguat adalah faktor yang paling kuat memicu ibu memilih tenaga penolong persalinan di antaranya adalah ibu termotivasi berdasarkan pengalaman melahirkan sebelumnya yang lancar, pengaruh bidan dan dukun itu sendiri, dan peran suami. Salah satu inovasi bidan memotivasi ibu bersalin ke bidan yaitu setiap ibu yang periksa di bidan, akan diantar staf kesehatan ke rumah masing-masing dan keringanan membayar seperti menyicil ataupun menggunakan kartu Askeskin. Sementara upaya dukun memotivasi ibu untuk bersalin dengan mereka adalah kesiapan dukun memeriksa ibu semenjak kehamilan 2 bulan, merawat ibu dan bayi sampai 40 hari, biaya pelayanan hanya seikhlasnya berapapun yang diberikan ibu bersalin. Sikap dukun yang baik dan biaya murah, menjadi daya tarik ibu bersalin memilih dukun bayi dari pada bidan saat persalinan. Salah satu faktor seseorang memilih pelayanan kesehatan dipengaruhi oleh faktor sosial, ekonomi dan lingkungan setempat. Hasil penelitian Eryando menunjukkan bahwa alasan utama informan memilih persalinan ke dukun bayi adalah biaya persalinan dan kemudahan transportasi. ${ }^{20}$

\section{KESIMPULAN}

Sebagian besar informan memilih dukun bayi sebagai tenaga penolong persalinan utama, karena tradisi setempat, dukun orang yang dituakan dan berilmu turun temurun. Informan memilih bidan, apabila persalinan mengalami kesulitan dan dukun tidak mampu menangani.

Faktor pemicu bagi ibu dalam memilih tenaga penolong persalinan adalah tingkat pendidikan dan jenis pekerjaan. Informan berpendidikan tinggi dan yang bekerja sebagai kader kesehatan memilih bidan sebagai tenaga penolong persalinan tinggi. Faktor pemungkin bagi ibu memilih tenaga penolong persalinan adalah ketersediaan tenaga penolong persalinan dan kemudahan transportasi ke tenaga penolong persalinan. Faktor penguat informan adalah 
penolong persalinan sebelumnya, peran suami, peran bidan dan peran dukun bayi.

Perlunya menggiatkan penyuluhan kepada masyarakat dan aparat setempat tentang pentingnya melahirkan dengan petugas kesehatan dan membangun kemitraan antara bidan desa dengan dukun bayi dengan saling menguntungkan, agar ibu bersalin termotivasi bersalin di bidan tanpa takut menyalahi tradisi yang ada. .

\section{UCAPAN TERIMA KASIH}

Ucapan terimakasih disampaikan kepada Prof. Sudarti Kresno atas masukan dalam penyusunan penelitian ini dan kepada Kepala Dinas Kesehatan Kabupaten Lampung Selatan dan jajarannya yang telah memberikan ijin dan mempermudah pelaksanaan penelitian.

\section{DAFTAR RUJUKAN}

1. Kementerian Kesehatan RI. Permenkes No. 39/2016, tentang pedoman penyelenggaraan program Indonesia sehat dengan pendekatan keluarga. Jakarta: Kementerian Kesehatan; 2016.

2. Departemen Kesehatan RI. Laporan riset kesehatan dasar (Riskesdas) 2010. Jakarta: Badan Litbangkes Departemen Kesehatan; 2010.

3. Kementerian Kesehatan RI. Laporan Tahunan. Jakarta: Direktorat Kesehatan Keluarga Kementerian Kesehatan; 2016.

4. Niana NR. Faktor yang Berhubungan dengan Pemberian ASI Eksklusif di Wilayah Puskesmas Sidotopo Wetan. Surabaya: Universitas Airlangga; 2011.

5. Lestari W, Soleha M, Ibrahim I, et al. Buku seri etnografi kesehatan ibu dan anak. Jakarta: Badan Litbangkes; 2012.

6. Dinas Kesehatan Lampung Selatan. Profil kesehatan 2008. Lampung Selatan: Dinas Kesehatan Lampung Selatan; 2008.

7. Dinas Kesehatan Lampung Selatan. Profil kesehatan 2017. Lampung Selatan: Dinas Kesehatan Lampung Selatan; 2017.

8. Rina Anggorodi. Dukun Bayi dalam Persalinan oleh Masyarakat Indonesia. Makara Kesehatan. 2009; 13(1): 9-14.
9. Amilda NL, Palarto B. Faktor-Faktor yang Mempengaruhi dengan Pemilihan Pertolongan Persalinan oleh Dukun Bayi. Semarang: Universitas Diponegoro; 2010.

10. Alhidayati, Asmuliyanti. Perilaku Ibu dalam Memilih Tenaga Penolong Persalinan di Wilayah Kerja Puskesmas Tembilahan Hulu Tahun 2016. Jurnal Kesehatan Komunitas. 2017; 3(5):182188.

11. Annisa N, Ike A.Tradisi Kepercayaan Masyarakat Pesisir Mengenai Kesehatan Ibu di Desa Tanjung Limau Muara Badak Kalimantan Timur Tahun 2008. Jurnal Kesehatan reproduksi. 2010; 1(1): 42-50.

12. Pramono, Sadewo. Analisis Keberadaan Bidan Desa dan Dukun Bayi di Jawa Timur. Buletin Penelitian Sistem Kesehatan. 2012; 15(3): 305313.

13. Green W. Laurence. Health education planning: a diagnostic approach. California: Mayfield Publishing Company; 1980.

14. Sukidjo Notoatmodjo. Pengantar pendidikan kesehatan dan ilmu perilaku kesehatan. Yogyakarta: Andi Offset; 1993.

15. Een K, Andi M, Caca S. Persepsi Ibu Hamil tentang Pemilihan Persalinan ditinjau dari Budaya Banggai di Wilayah Kerja Puskesmas Lantibung. Jurnal Mitrasehat. 2018; 8(2); 310323.

16. Rangkuti Sadiyah. Mengurangi Resiko Kematian Ibu Melahirkan. Jurnal Ilmiah Research Sains. 2015; 1(3): 16-21.

17. Departemen Kesehatan RI. Pedoman Kemitraan Bidan dengan Dukun. Jakarta: Direktorat Jenderal Bina Kesehatan Masyarakat, Departemen Kesehatan; 2008.

18. Ditha P, Sri Seti I. Komunikasi Terapeutik Bidan dan Paraji sebagai Kader dalam Optimalisasi Pelayanan Kesehatan Ibu Hamil. Jurnal Komunikasi. 2017; 9(1): 25-38.

19. Lia Amalia. Faktor-Faktor Yang Mempengaruhi Ibu Dalam Pemilihan Penolong Persalinan. Gorontalo: Universitas Negeri Gorontalo; 2011.

20. Eryando, Tris. Reason Behind the Utilization of Maternal Health Services. Jakarta: Fakultas Kesehatan Masyarakat Universitas Indonesia dan Direktorat Jenderaln P2M PL Departemen Kesehatan; 2006. 